\title{
Simple Smart Piezoelectric Bolt Sensor for Structural Monitoring of Bridges
}

\author{
N. Shimoi ${ }^{1}$, C. H. Cuadra ${ }^{1}{ }^{* *}$, H. Madokoro ${ }^{1}$, M. Saijo ${ }^{2}$ \\ ${ }^{1}$ Faculty of System science and Technology, AkitaPrefecturalUniv ersity, Yurihonjo, Jap an \\ ${ }^{2}$ Department of Development Planning, OYO Corporation, Tsukuba, Jap an
}

\begin{abstract}
Ageing and heavy traffic affect the structural condition of bridges and evaluation of their structural integrity is an important task to ensure their safety utilization. Structural health monitoring constitutes a method for continuous evaluation of the condition of a target construction and for this purpose many sensors and systems have been developed. In this research a simple s mart piezoelectric sensor was develop and description of the proposed system, basic experiments to estimate the properties of the sensor and preliminary application to evaluate the dynamic characteristics of a target bridge are discussed. The applicability of this new sensor to estimate appropriately the structural condition of bridges was verified by comparing the measurements results with those obtained by means of more sophisticated sensors.
\end{abstract}

Keywords Smart Bolt Sensor, Structural Health Monitoring, Dynamic Characteristics of Bridges

\section{Introduction}

After the Pacific War, in Japan many building were constructed as a part of the reconstruction program in itiated by the Japanese Government. Therefore old buildings of that date are now in danger due to the deterioration of their structures. On the other hand in the decade of 1980 of the last century constructions of large projects of building and bridges were initiated. Then high demand of materials, in special for reinforced concrete structures, induced the used of sea sand which contains salts that in reaction with water and cement originates the corrosion of the steel reinforcement. Outside Japan an example of the necessity of health monitoring was evident in the collapse of the I-35W Mississippi River bridge. During the evening rush hour on August 1, 2007, the bridge suddenly collapsed, killing 13 people and injuring 145. In the case of Japan the Ministry of Land and Transportation has performed a study of the vulnerability of bridges and 121 cases of bridges in danger have been reported. The risk of the bridges is due to the deterioration of aged concrete bridges (weathering) and corrosion of steel bridges.

A continuous or real time structural health monitoring could help to prevent damages. Monitoring systems already exist however they are in general designed to be installed in new structures and are expensive. For existing old structures, simple and cheap sensor systems are required.

* Corresponding author: carlos@akita-pu.ac.jp (C. H. Cuadra)

Published online at http://journal.sapub.org/instrument

Copyright (C) 2012 Scientific \& Academic Publishing. All Rights Reserved
In this research a new sensor that is based on piezoelectric cable inserted into a bolt is developed and its applicability to perform health monitoring of structures is verified by means of a shaking table test series. Then the proposed deviceis employedtocarryoutafield measurement of the dynamic characteristics of a provisional bridge located in Yurihonjo city, Akita prefecture, Japan. The results obtained with this new simple smart sensor are comparable with those obtained with more sophisticated and expensive commercial sensor.

\section{Development of the Simple Smart PiezoelectricBolt Sensor}

\subsection{Characteristics of the Measurement Device}

The piezoelectric-bolt sensor is shown in Figure 1, and contains in its interior a piezoelectric cable which is covered by urethane resin. Then the nominal diameter of the bolt sensor is $15 \mathrm{~mm}$ and its longitude is $80 \mathrm{~mm}$. However to fix the sensor an external metal envelope, forming the bolt spiral, covers the system and the nominal diameter results in $20 \mathrm{~mm}$ (M20). The scheme of the piezoelectric cable is shown in Figure 2 which can be connected to a computer board by means of a $4 \mathrm{~m}$ length cable with $5.6 \mathrm{~mm}$ of diameter. This proposed simple sensor can measure strain by the change of the voltage in the piezoelectric cable when this cable is deformed by an external action. Therefore relative displacements and vibration of bridge joints can be easily measured. Moreover, the characteristics of the sensor like sampling frequency permits to send the signal to a four channels computer board for automatic data acquisition. In 
this way signals from four sensors can be recorded simultaneously with a direct input computer board.

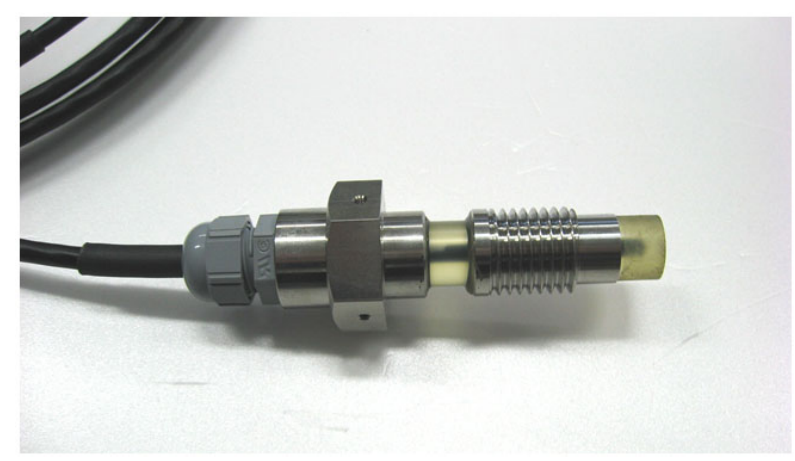

Figure 1. The Simple smart bolt sensor

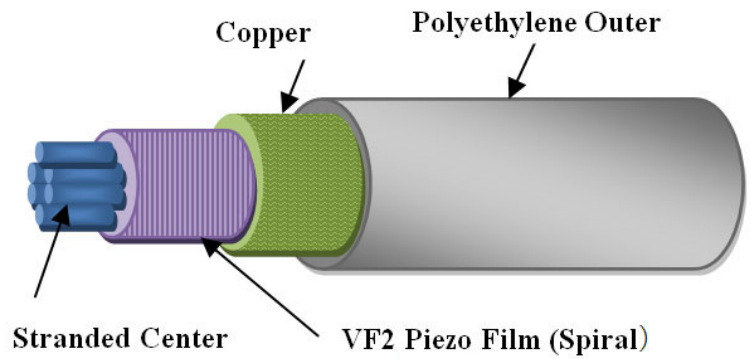

Figure 2. Piezoelectric cable sensor ${ }^{(9)}$

First, the proposed sensor was tested under harmonic excitation using a vibration machine, and response of the sensor is compared with the amplitude and frequency of the input signals. For in-situ test on bridge structure, the sensor was installed together with a high precisioncommercial accelerometer to compare both results. For the proposed sensor, data was recorded using a wireless system (Zigbee wireless module). Source energy (lithium battery pack Lipo2000mAh) is required for the board that receives the signal from the sensor and transmits it to the computer for data acquisition. Personal computer required its own source of energy for acquisition and posterior data processing. Figure 3 shows the general scheme of the data acquisition system using the proposed sensor.

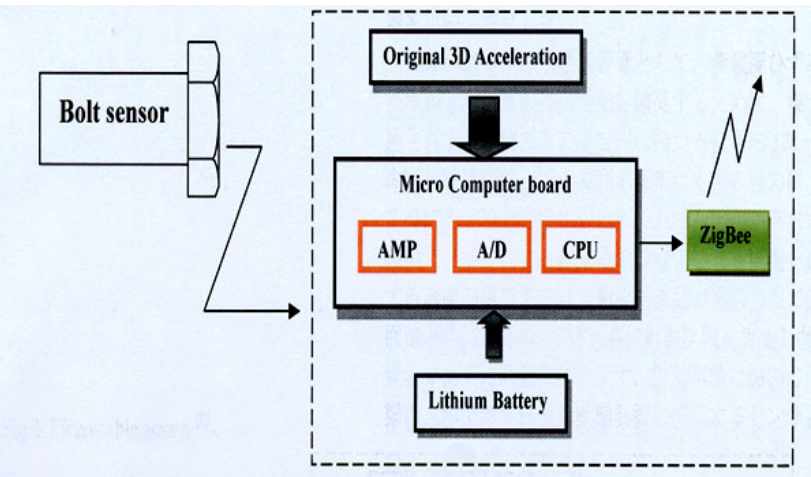

Figure 3. Block diagram of the experimental system

\subsection{Sensor Installation and Me as urement Method}

In general, small vibration and small displacements of bridges are measured by means of high precision devices like accelero meters, laser displacement transducers, optical fibre, etc. These measurements have an error of the order of $5 \mu \mathrm{m}$ which represents a high precision measurement. In the case of the proposed sensor which is intended to be used for continuous real time health monitoring, the piezoelectric core cable of the bolt sensor emits a signal that corresponds to a change of the voltage when the bolts suffers a deformation. To permit the bolt to experiment a deformation it must be installed in the target structure inside a hole and then fixed by a nut. In principle, the change in voltage corresponds to a shear deformation of the bolt.

Figure 4 shows the general layout of the vibration test of the bolt sensor using a small shaking table machine. Figure 5 shows a detail of the installation of the smart bolt sensor which is subjected to a shear deformation induced by the vibration devices. The test was performed at fixed amplitude and therefore it is supposed that the sensors behave under a fixed harmonic force. For comparison displacement of the vibration machine was measured by mean of a laser displacement transducer.

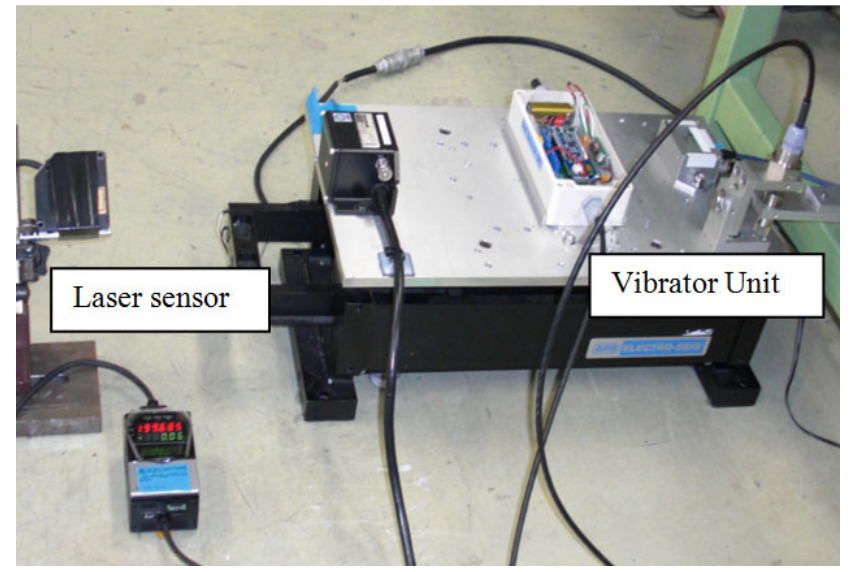

Figure 4. General layout of the vibrat ion test

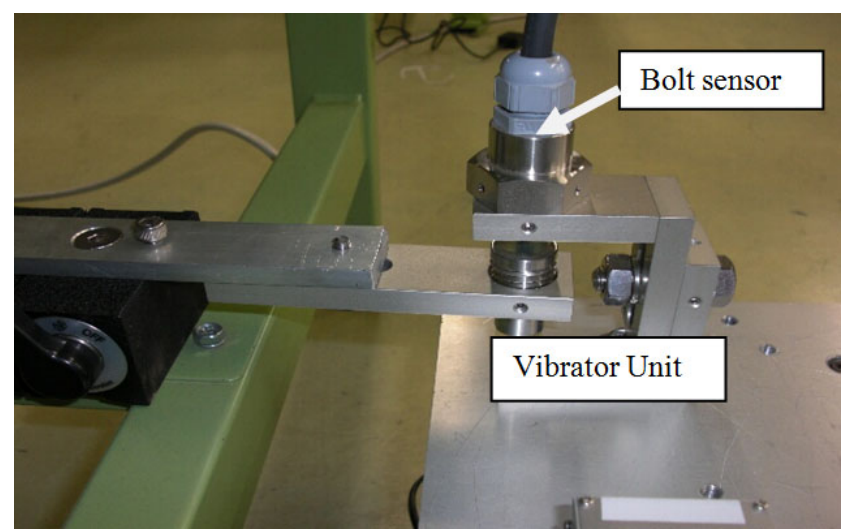

Figure 5. Detail of the bolt sensor setup for vibration test

The proposed sensor is designed to be used to estimate the probable failure or collapse of structures and specifically the failure of bridge structures. That is, a difference than the high precision sensors which are used to estimate exactly the response of the bridge under normal loads, the bolt sensor is proposed to detect extremely behaviour and deformation that could indicate the imminent 
failure or collapse of bridges. For this purpose the bolt sensor must be installed in critical portion of the target structure and continuous real time monitoring using the wireless signal transmission and automatic data acquisition system should permit to tailor the objective.

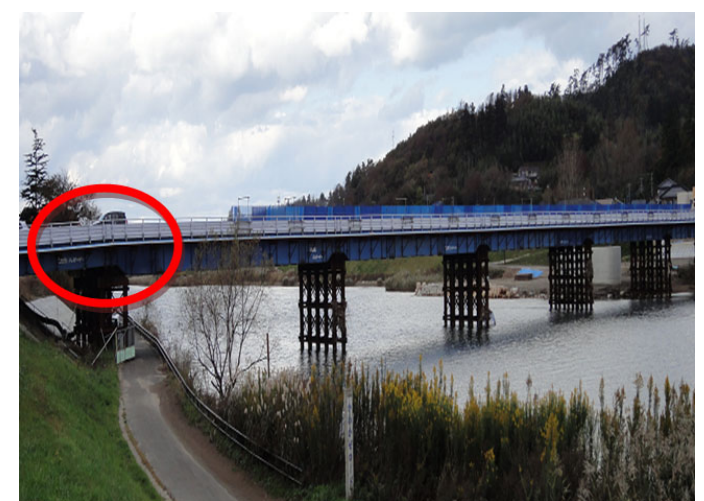

Figure 6. Selected bridge and location of the point for measurements

For in-situ measurements on real structure, the temporary bridge located at Yurihonjo city, Akita Prefecture, Japan was selected, and sensor was installed in a joint of the bridge as is shown in Figure 6. The bridge spans over the Koyoshi river and has $175 \mathrm{~m}$ in totallength. For comparis on high precision accelerometers were also installed and measurements were performed during 3 days from 9:00 am to $4: 00 \mathrm{pm}$. In addition video recorder was also installed to verify the type of vehicles which produce the vibration of the bridge.

The evaluation of the performance of the sensor has three steps: 1) Comparison of the displacement measurements during vibration test with the output voltage of the sensors, 2) Analysis of the sensor output according to the amplitude variation during vibration tests and 3) Comparison of results from high precision devices and bolt sensor measurements during vibration of temporary Yuri bridge under vehicles excitations.

\section{Discussion of Results}

In the case of vibration test the results for $0.5 \mathrm{~mm}$ of peak to peak amplitude and constant frequency of $2 \mathrm{~Hz}$ is shown in Figure 7. The figure shows the results obtained by the laser displacement transducer compared with the results from the bolt sensor. Good correlation can be observed from both results and the vibration characteristic is also clearly detected by the proposed simple s mart bolt sensor.

Vibration test were performed for $0.25 \mathrm{~mm}, 0.5 \mathrm{~mm}$ and 1 $\mathrm{mm}$ of a mp litude respectively.For each amp litude value the frequency was set up from $1 \mathrm{~Hz}$ to $15 \mathrm{~Hz}$. The curves that relate the frequency, amplitude and the maximum output voltage of the sensor are shown in Figure 8.
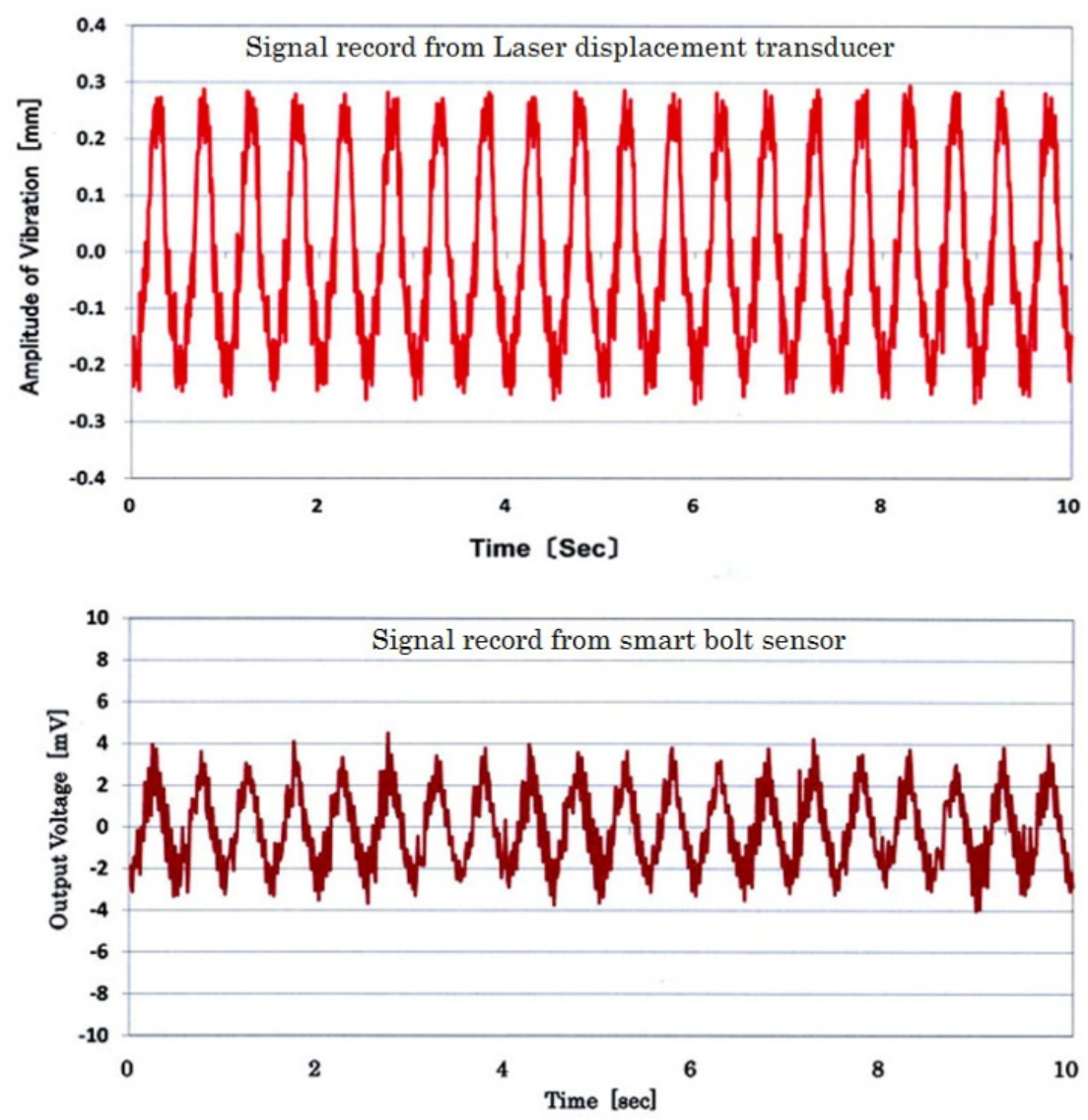

Figure 7. Comparison of measurement results from laser displacement transducer with those obtained from proposed smart bolt sensor during vibrat ion test 


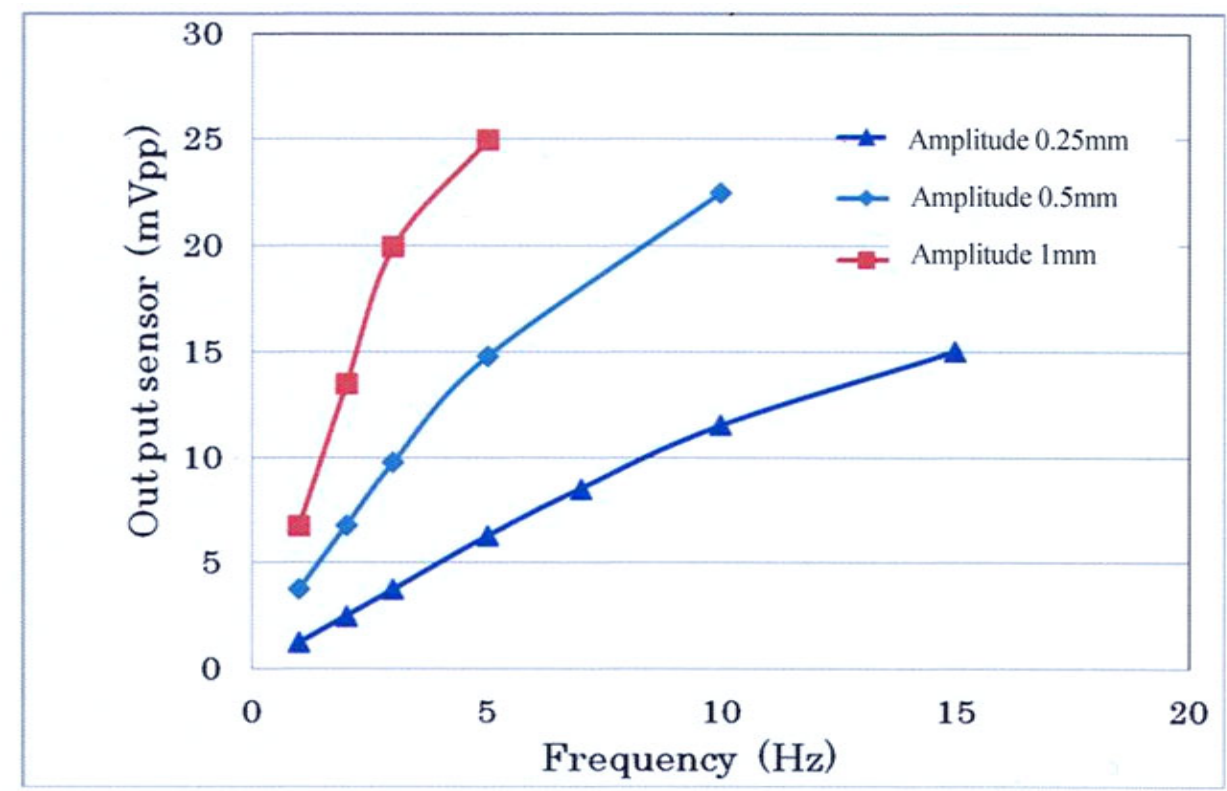

Figure 8. Relationship between frequency, output voltage of sensor and amplitudeof the vibration

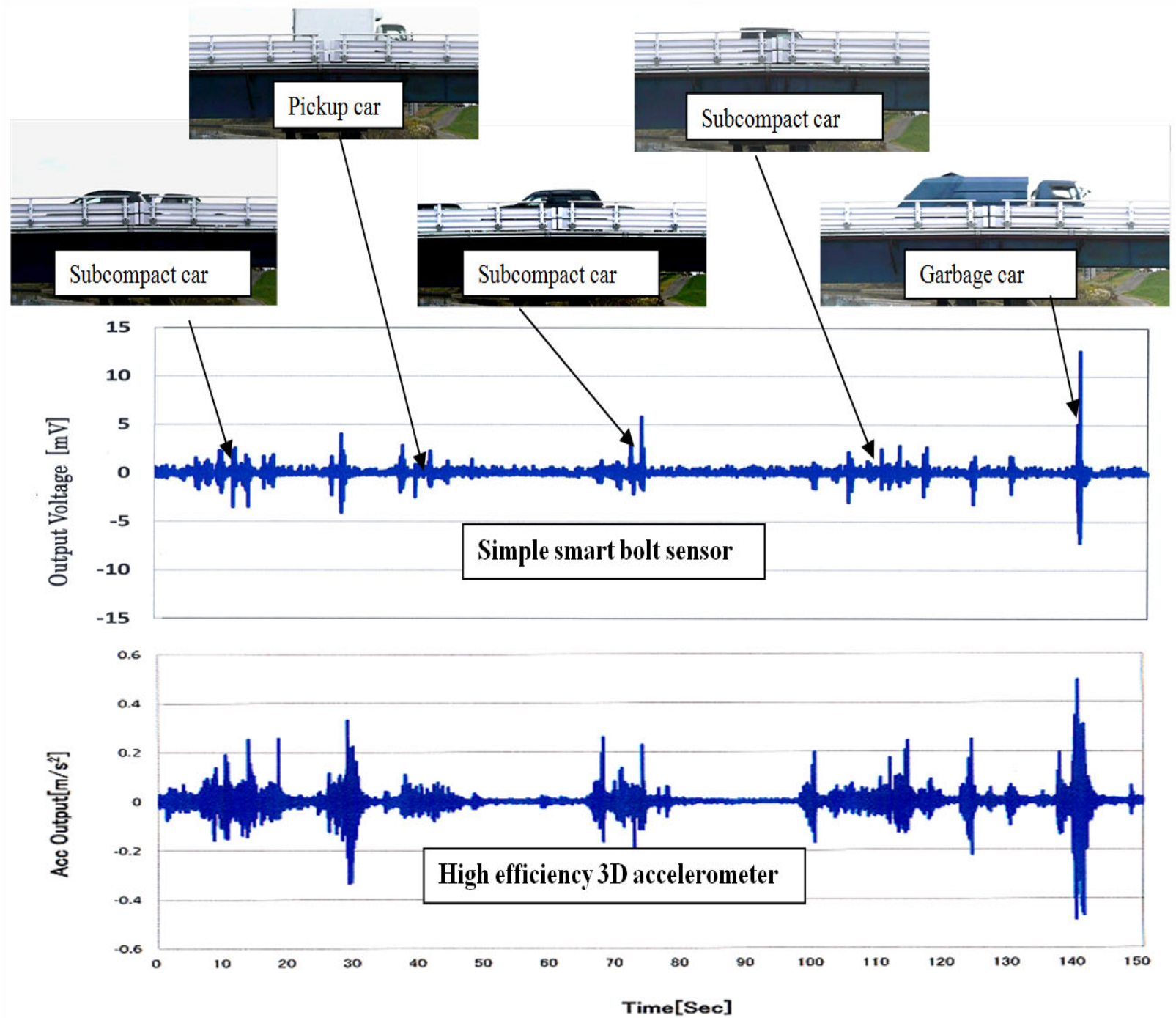

Figure 9. Comparison of measurement results from simple smart bolt sensor with those obtained from high efficiency $3 \mathrm{D}$ accelerometer during struct ural monitoring of a bridge 
From Figures 7 and 8 the fo llowing relationships between the output voltage of the sensor and the amplitude of vibration are obtained.

$$
\begin{gathered}
V_{\text {out }} \approx D \cdot\left(K \cdot f_{n}+4\right) \\
D \approx \frac{V_{\text {out }}}{K \cdot f_{n}+4}
\end{gathered}
$$

where $V_{\text {out }}$ is the output voltage in $\mathrm{mV}, K$ is a coefficient equal to $4.5, f_{n}$ is the frequency of the input load, and $D$ is the amp litude of the vibration in $\mathrm{mm}$.

Figure 9 shows the comparison of measurements performed at temporary bridge located in Yurihonjo city, Japan. The results from simple s mart bolt sensor and results from $\mathrm{h}$ igh precision $3 \mathrm{D}$ accele ro meters are comparable and general tendency which permits to identify the vibration originated by various kind of vehicles were obtained. The types of vehicles were identified by the analysis of the video record that was synchronized with the measurements devices. For example, the pass of heavy vehicle like a garbage car was clearly detected. Therefore, by comparis on it can be stated that the remarkable vibration due to the vehicle passing is well captured by the proposed sensor and applicability for real time vibration monitoring has been verified.

\section{Conclusions}

To investigate the structural condition of bridges or any other structure, usually high precision or high performance measurement devices are employed. However, these devices are expensive and carefully handle must be taken into account since they are delicate instruments to be used for a permanent or long term monitoring. In this research a new smart simple piezoe lectric sensor and its corresponding data acquisition system were developed to be used for real time structural health monitoring of structures. Installation of the system in selected portion of structures would permit to perform the monitoring of the structural condition, in special after an earthquake event and in the case of bridges to investigate their behaviour under vehicle loads and to detect potential failures due to ageing.

Proposed strain bolt sensor was installed in a joint of a temporary bridge and measurements of the output voltage have permitted to infer the amplitude and frequency of the vibration and therefore to obtain the dynamic characteristics of the structures under investigation.

The response of the proposed sensor for different type of vehicles passing the bridges is similar to that detected by means of high sensitivity accelerometers. Therefore the applicability of the proposed sensor and measurement system was verified.

\section{ACKNOWLEDGEMENTS}

The authors acknowledge Akita Prefectural University President Project for the support of the Special Research on Battery Less Sensor for Structure Health Monitoring, under which this research was conducted.

\section{REFERENCES}

[1] Ministry of Land, Infrastructure and Transports report: Research on upgrading of soundness evaluation method for highway PC bridge. Technical Note of. National Institute for Land and Infrastructure Management, No.623, pp6--14, (2010), (in Japanese).

[2] The Asahi shim bun: News paper column, Land transport services development table 121 bridge (2009), (in Japanese).

[3] Civil engineering structure Committee members bridge design technology Subcommittee: Subcommittee report of FRP bridge design technology, University of Tokyo press (2004), (in Japanese).

[4] K. Ono: Study of Technologies to Extend the Life of Constructions, Society of the New Urban socio-technical Integration Creation, The second technical seminar of new urban society (2003), (in Japanese).

[5] M. Nakamura: Development of Structural Health Monitoring System, A measurement and control, Vol.41, No 11, pp 819-824, (in Japanese).

[6] Fu-kouChang:The Demands and Challenges, Proceeding ofthe3rd International Workshop on Structural Health Monitoring,Stanford University, Stanford, CA,(2001)

[7] M. Nakamura and Y. Yasui: Damage Evaluation of a Steel Structure Subjected to Strong Earthquake Motion Based on Ambient Vibration Measurements, Journal of structural and construction engineering. Transactions of AIJ, Vol.517, pp.61--68 (1999), (in Japanese).

[8] T. Okabayashi, T. Okumatsu, and Y. Nakamiya: Experimental Study on Structural Damage Detection Using the High Accurate Structural Vibration-Estimation System, Journal of Structural Engineering A, Vol.51A, pp.479--490 (2005), (in Japanese).

[9] Tokyo Sensor Co., Ltd: PIEZO FILM TECHNICAL MANUAL, V1.0,R1, 17/18 (2001), (in Japanese).

[10] Y. Nitta, K. Imamoto, and A. Nishitani: Structural Health Monitoring Utilizing Piezoelectric Cable, Summaries of technical papers of Annual Meeting Architectural Institute of Japan. B-2, Structures II, Structural dynamics nuclear power plants 2006, pp. 891--892, (2006), (in Japanese).

[11] S. Kurosaki, Y. Sasaki, and S. Izumi: Trial of Measurements for Axial Force of Bolt Using Piezo Cable, Journal of the Japanese society for non-destructive inspection, Vol. 56, No. 3, pp. 149--154 (2007), (in Japanese).

[12] T. Mikami and T. Nishizawa: Health Monitoring of High-Rise Building with Fiber Optic Deformation Sensor, Transactions of the Japan Society of Mechanical Engineers. C 75(750), 249-255, 2009, (in Japanese). 
[13] Tokyo Sensor Co., Ltd: Piezoelectric Cable, Traffic Sensors, 18/19 (2010), (in Japanese).

[14] Carlos Cuadra; "Vibration Characteristics of an Old Steel Bridge" Sustainable Infrastructure Environment Friendly, Safe and Resource Efficient, IABSE Symposium Bangkok 2009, Abstract pp. 246-247. CD-ROM paper.

[15] N. Igarashi, C. H. Cuadra, and S. Oshikiri, "Dynamic properties of traditional wooden temples located in Yurihonjo city, Japan", 14th European Conference on Earthquake Engineering (14ECEE), Ohrid, Macedonia August 30 - September 3, 2010. Paper Number: 392.

[16] Carlos HumbertoCuadra, "Vulnerability of Adobe-Quincha buildings located at Lima Historic Centre"; The 2011 World Congress on Advances in Structural Engineering and Mechanics, Sheraton Walker Hill Hotel, Seoul, South Korea 18 - 22 September 2011.

[17] Yuta Yamada, N. Shimoi, C. H. Cuadra, Naota Miyahara, Takashi Doko "Forced vibration test on wooden model to simulate the seismic behavior of traditional Japanese wooden shrines", Proceedings of the 15th World Conference on Earthquake Engineering, September 24-28, 2012, Lisbon, Portugal, Paper No. 1721.
[18] C. H. Cuadra, JunyaMeguro; "Evaluation of the dynamic characteristics of a base-isolated low-rise RC building after the Great East Japan Earthquake", Proceedings of the 15th World Conference on Earthquake Engineering, September 24-28, 2012, Lisbon, Portugal, Paper No. 1284.

[19] H. Madokoro, Y. Utsumi, and K. Sato, "Unsupervised Scene Classification Based onContext of Features for a Mobile Robot," Proc. 15th International Conference on Knowledge Based and Intelligent Information \& Engineering Systems (KES), Part I,pp.446-455, Sep. 2011.

[20] Katsumi WASAKI, Nobuhiro SHIMOI, “A Practice of Smart Sensing System for BuriedMines Detecting based on Active Infrared Thermography Approach" International Journal of Computational Intelligence: Theory and Practice, 4(1)pp29-37( 2009)

[21] Nobuhiro.Shimoi,YoshihiroTakita,"Remote mine sensing technology using a MobileWheeled Robot RAT-1", Proceedings of the International Conference on Control Automation and Systems. ICCAS 2010, pp TE06-4(5) (2010.10) 